\title{
An analytical cross-sectional study of peer pressure on adolescents
}

\author{
Anisha Khan, Manisha Jain*, Chhaya Budhwani
}

Department of Obstetrics \& Gynecology, PCMS \& RC, Bhopal, Madhya Pradesh, India

Received: 02 March 2015

Revised: 16 March 2015

Accepted: 18 April 2015

\author{
*Correspondence: \\ Dr. Manisha Jain, \\ E-mail: mnishu2002@yahoo.com
}

Copyright: (c) the author(s), publisher and licensee Medip Academy. This is an open-access article distributed under the terms of the Creative Commons Attribution Non-Commercial License, which permits unrestricted non-commercial use, distribution, and reproduction in any medium, provided the original work is properly cited.

\begin{abstract}
Background: Friendships constitute an integral part of adolescent growth and development. As the teens explore their identity towards functional independence, teen peer relationship acquires an important role. Contrary to prevailing beliefs, peer pressure can have both a positive and negative impact on youths.

Methods: A school based cross sectional study carried out on adolescents falling between the age group of 11 to 19 years using a pre-designed written questionnaire. The data obtained were analyzed using descriptive analytical methods.

Results: The mean age for all was 17 years (Range 15-19 years). Adolescents preferred long term friendships (52\%), opposite gender $(66 \%)$ and similar socioeconomic status $(43 \%)$ while making friendships. Majority admitted to have good quality time spent with parents $(81 \%)$ and parents as the most influential persons in their lives $(85 \%)$. While, teen peer relationship can result in improvement in academic performance (96\%), skill and personality development $(96 \%)$ it can also have negative influences like alcohol intake (52\%), cigarette smoking (55\%) and other misconducts $(55 \%)$.

Conclusions: Though, it may appear that teens are all influenced by their peers, parents continue to be the most influential persons in their lives. Peer friendships although thought of as all negative impact, can also have a positive effect on youth development.
\end{abstract}

Keywords: Adolescent, Peer pressure

\section{INTRODUCTION}

Adolescence is a period of transition from childhood to adulthood and refers to the age group of 10-19 years. ${ }^{1}$ The term "adolescence" derived from Latin means "to grow and to mature". This period characterized by significant physical and psychological changes is considered as an important milestone in one's development.

With one-fifth of total Indian population comprising of adolescents, the role of adolescent health in shaping the overall health of the nation cannot be overemphasized. ${ }^{2}$ The pattern of behavior, lifestyle and overall health of teens gets affected by multiple factors namely, individual, family, school, community, society and most importantly peers. As the teens grow and enter this critical phase of life, peers start acquiring increasingly important role in their lives. Friendships form an integral component of youth development towards the final acquisition of adulthood. As the teens explore their identity and seek social acceptance along with functional independence, they start developing more complex and intimate friendships which often last forever.

Peer influence refers to the practice of adopting a particular type of behavior, dress or attitude in order to be accepted as the part of a group of one's equals or peers. 
When the influence is severe enough that youth finds it hard to resist or is compelled to follow a particular uncomfortable behavior it is termed as peer pressure. Peer influence, often perceived as the one compelling the youth to engage in unhealthy and unsafe behavior can have a positive impact as well. Peer influence actually is more complex than the common adult perception of negative influence forcing teens to reject their family values or engage in high risk behaviors. It is also not as straight as a process where teens are passive recipient of negative influence.

The current study was undertaken to explore the various determinants of teen peer relationship and their effect on adolescents.

\section{METHODS}

This was a school based cross sectional study carried out among the students of two urban English medium schools of Bhopal falling between the age group of 10-19 years. The study was approved by institutional ethics committee. A pre-designed written questionnaire approved by the subject experts in English language was distributed among the students after a brief explanation about the various items of the questionnaire.

The participation in the study was voluntary and the students could opt out of the study anytime they willing to do so. All participants were ensured about the anonymity and could opt out of any question they did not willing to answer. The items in the questionnaire were related to their relationships with parents and peers and the effect of both on their life-style and behavior.

The data were analyzed using descriptive analytical methods like, range, mean and percentage frequency.

\section{RESULTS}

A total of 90 students between the age group of 10-19 years participated in the study. The mean age for all was 17 years (Range 15-19 years). Almost all participants responded to all items in the questionnaire as they were ensured about the anonymity. Our observations are summarized as follows in different tables.

\section{Characteristics of peers}

On responding about the source of friends, majority $(48 \%)$ had got acquaintance with their friends through parental relations while $40 \%$ chose school mates as their close friends. Adolescents preferred long term friendships $(52 \%)$ over short term $(45 \%)$ or frequently changing $(3 \%)$ friendships. Sixty participants $(66 \%)$ preferred to have friends from opposite gender while $33 \%$ went for friends with same gender. About half $(43 \%)$ responded to have friends from same socioeconomic status while about remaining half $(43 \%)$ went for peers with higher socioeconomic status (Table 1).

Table 1: Showing characteristics of peers $(n=90)$.

\begin{tabular}{|lllllll|}
\hline Showing characteristics of peers $(\mathrm{n}=90)$ & & & & \\
\hline Gender preference & Opposite & $60(67 \%)$ & Same & $30(33 \%)$ & Neither & Nil \\
\hline Socioeconomic status & Similar & $43(48 \%)$ & Higher & $43(48 \%)$ & Lower & $04(4 \%)$ \\
\hline Source of friends & School & $36(40 \%)$ & Parental & $43(48 \%)$ & Relatives & $11(2 \%)$ \\
\hline Type of friendship & Long term & $47(52 \%)$ & Short term & $40(45 \%)$ & Either & $13(3 \%)$ \\
\hline
\end{tabular}

\section{Teen parental relationship}

Almost all $(81 \%)$ subjects admitted to have good quality time spent with their parents while ten $(11 \%)$ had formal relationship and seven $(8 \%)$ responded to have overall poor relationship with their parents. About $75 \%$ admitted that they could communicate freely with their parents while six $(7 \%)$ were hesitant to talk to their parents about most of the matters. Majority $(85 \%)$ responded that their parents were the most influential person in their lives followed by their friends (15\%).

About half $(52 \%)$ admitted that majority of their decisions were taken by their parents and $48 \%$ responded that most of their decisions were taken by themselves. However, none opted that their decisions were taken jointly (Table 2).

Table 2: Showing determinants of teen parental relationship $(\mathbf{n}=90)$.

\begin{tabular}{|lllllll|}
\hline Showing determinants of teen parental relationship $(\mathrm{n}=90)$ & & & & \\
Quality of time spent with parents & Good & $73(81 \%)$ & Average & $10(11 \%)$ & Poor & $7(8 \%)$ \\
\hline Communication with parents & Freely communicate & $67(75 \%)$ & Formal conversation & $17(18 \%)$ & Poor & $6(7 \%)$ \\
\hline Decision taking influenced by & Parents & $77(85 \%)$ & Friends & $13(15 \%)$ & Teachers & Nil \\
\hline Final decisions taken by & Parents & $47(52 \%)$ & Self & $43(48 \%)$ & Jointly & Nil \\
\hline Conflicts with parents & Common & $63(70 \%)$ & Rare & $20(22 \%)$ & Never & $7(8 \%)$ \\
\hline
\end{tabular}




\section{Teen peer relationship}

On enquiring about the relationship of teens with their peers, $70 \%$ responded that they made friends for moral support, $14 \%$ had friends as they shared academic interests, $8 \%$ wanted companionship while another $8 \%$ had friends for economic support. Majority (66\%) reported their self-esteem as moderate, $26 \%$ rated it as good while $8 \%$ thought that they had low self- esteem. About half (48\%) agreed that they were able to resist the negative peer influence often but not always, $26 \%$ were able to do it always while remaining $26 \%$ were never able to resist negative influence. About half $(47 \%)$ thought that the relationship of their parents with their peers were good, $45 \%$ thought that it was very good while only $7(8 \%)$ reported it to be poor (Table 3$)$.

Table 3: Showing determinants of teen peer relationship $(n=90)$.

\begin{tabular}{|llllllll|}
\hline $\begin{array}{l}\text { Showing determinants of teen peer relationship (n=90) } \\
\text { friendship }\end{array}$ & $\begin{array}{l}\text { Moral } \\
\text { support }\end{array}$ & $63(70 \%)$ & $\begin{array}{l}\text { Similar academic } \\
\text { interest }\end{array}$ & $13(14 \%)$ & $\begin{array}{l}\text { Need for } \\
\text { companionship }\end{array}$ & $7(8 \%)$ & $\begin{array}{l}\text { Economic } \\
\text { reasons }\end{array}$ \\
\hline $\begin{array}{l}\text { Self-esteem as } \\
\text { rated by teens }\end{array}$ & High & $23(26 \%)$ & Average & $60(66 \%)$ & Low & $7(8 \%)$ \\
\hline $\begin{array}{l}\text { Resistance to } \\
\text { negative peer } \\
\text { influence }\end{array}$ & Always & $23(26 \%)$ & Often & $44(48 \%)$ & Never & $23(26 \%)$ \\
\hline $\begin{array}{l}\text { Parent Peer } \\
\text { relationship }\end{array}$ & Good & $40(45 \%)$ & Fair & $43(47 \%)$ & Poor & $7(8 \%)$ \\
\hline
\end{tabular}

\section{Effect of peer influence on teen behaviour}

Almost all admitted to have improvement in academic performance (96\%), skill and personality development (96\%) because of their friends while $81 \%$ reported to have improved confidence after friendship. However, teens also admitted to have negative influence of peers on them like involvement in alcohol intake (52\%), cigarette smoking (55\%) and other misconducts (55\%) (Table 4).

Table 4: Showing various effects of peer influence on teen behavior.

\begin{tabular}{|lllll|}
\multicolumn{1}{c}{ Yes } & No \\
\hline Academic improvement & 87 & $96 \%$ & 3 & $4 \%$ \\
\hline Skill development & 87 & $96 \%$ & 3 & $4 \%$ \\
\hline Personality development & 87 & $96 \%$ & 3 & $4 \%$ \\
\hline Confidence improvement & 73 & $81 \%$ & 17 & $19 \%$ \\
\hline Alcohol intake & 47 & $52 \%$ & 43 & $48 \%$ \\
\hline Cigarette smoking & 50 & $55 \%$ & 40 & $45 \%$ \\
\hline Other misconducts & 50 & 555 & 40 & $55 \%$ \\
\hline
\end{tabular}

\section{DISCUSSION}

Adolescence is a period characterized by rapid biological, cognitive and socio-psychological development making this population subgroup susceptible to a spectrum of physical and mental health related problems. As adolescent health lays foundation for future adult health, this period of transition and turmoil is being increasingly recognized as a window of opportunity to steer the overall growth and development of the society.
Friendships form an important aspect of adolescence. As the teens enter the adolescence and explore the pathways of adulthood, they make many close friends. More often they have friends belonging to multiple groups but of similar demographics and interests. The friendships may vary from long term ones to ones that are constantly changing. In our study, about half preferred to have long term $(47 \%)$ friendship and with peers of similar socioeconomic status (48\%). Majority (66\%) preferred to have friendship with opposite gender.

As the teen advances, teen parental relationship acquires new dimensions. Often, teens start spending more time with their friends and become increasingly autonomous. More than often this raises a concern among parents that teens may reject their values or may just cut off the familial ties. This parental concern is characteristically reflected as an increase in frequency and intensity of conflicts between teens and their parents. However, irrespective of the parental fears, teens continue to look towards their parents for most of the decisions and parents continue to be the most influential and significant role models in their lives. In our study, most (81\%) subjects admitted to have good quality relationship with their parents and about three-fourth admitted that they could communicate freely with their parents. Majority $(80 \%)$ opted that their parents were most influential persons in their lives and among nearly half (52\%) the major decisions were taken by their parents. Ryan R M and Lynch JH also stated in their study that the successful transition to autonomy and adulthood is facilitated by secure attachment and emotional connectedness with parents. ${ }^{3}$ Ladd \& Pettit were of the opinion that the secure attachments with parents are associated with less engagement in high risk behaviors, fewer mental health problems and enhanced social skills and coping 
strategies. Parents' involvement in their teens' peer relationships, such as providing guidance and support, is related to adolescents' peer relationships and their social competence. ${ }^{4}$ Parke and colleagues proposed a model of parenting that includes parents' roles as "managers of their children's social lives" as a distinct aspect of the parent-child relationship. ${ }^{5}$ Adolescents' perceptions of low parental caring, difficulty talking to their parents about problems, and valuing their friends' opinions for serious decisions were significantly associated with compromised behavioral and emotional health. Interventions aimed at improving the parent-child relationship may provide an avenue toward preventing health risk behaviors in youth. ${ }^{6}$

Adolescents have always been vulnerable to peer influence although the kind of peer influence and the response to it may vary from time to time. Contrary to the stereotyped impression of all negative influences, peer influence can be a much complex phenomenon. While it can lead teens to engage in unhealthy and unsafe behaviors, it can also motivate youth towards positive and productive endeavors. Peer friendships can give youth the required space to explore their identity, learn about the social norms and may also provide support to take the challenges of adolescence. In a meta-analysis conducted by Ide et al friends were similar in regards to the academic achievement and college aspirations among the ten studies. ${ }^{7}$ Landau supported the conclusion by stating that students who care about learning are more likely to be associated with peers who share this interest in academics than those who have less interest in learning. ${ }^{8}$ He also stated that an adolescent's expectancy of success was the primary predictor of academic efforts and grades. Ryan found that peer groups were influential regarding changes in students' intrinsic value for school as well as achievement. ${ }^{7}$ In our study, $70 \%$ participants made friendship seeking moral support while $14 \%$ had common academic interests. Ryan et al concluded that the personal value that an individual attaches to a characteristic may affect the individual's response to change. Often, high value results in resistance to change while low value results in receptiveness to change ${ }^{9}$ In our study, about half (48\%) agreed that they were able to resist the negative peer influences most of the times but not always while $26 \%$ couldn't resist the negative influences at all. Also, we observed that peer pressure was responsible for improvement in academics in 96\%, skill and personality development in $96 \%$ and improved self confidence in about $80 \%$ of participants.

Quite often it is presumed that peers do not allow adolescents to be "themselves" and rather compel them to put on an act to gain acceptance in the peer group. Jason Chein et al. posited that the risk-promoting effect of peer presence on adolescent decision-making could arise from a neural 'vulnerability' that emerges due to the discordant maturation of the brain systems that support decisionmaking. ${ }^{10}$ There is much evidence that adolescent drinking behavior is influenced by their parents and peers. ${ }^{11}$ On one hand, the use of alcohol by peers and getting acceptance from peers when drinking contributes to adolescent alcohol use. ${ }^{12}$ While, on the other, greater peer disapproval of heavy drinking results in less alcohol use and less heavy episodic drinking among adolescents. In our study, peer influence resulted in alcohol intake among 52\%, cigarette smoking in 55\% and other behavioral misconducts in $55 \%$ of study participants. Peer pressure is associated with pre-marital sexual debut as well. Youth who had peer pressure were three times more likely to initiate pre-marital sexual debut than their counterparts. ${ }^{13,14}$ Though little is known about the variable individual's susceptibility to peer influence, one of the most consistent and potent predictors of adolescents' engagement in aggressive and health-risk behaviors is the extent to which adolescents' peers engage in similar behaviors. ${ }^{15}$

\section{CONCLUSIONS}

Adolescent teens have multiple layers and groups of friendships. More than often teens tend to choose those who are similar to them. Although, it may appear that teens are influenced by their peers, parents continue to be the most influential persons in their lives. Parents who continue to communicate with their teens, despite the increasing conflicts, actually maintain closer relationships with their wards. Peer friendships though often rated as all negative impact can also have a healthy and positive effect on youth development.

Funding: No funding sources

Conflict of interest: None declared

Ethical approval: The study was approved by the institutional ethics committee

\section{REFERENCES}

1. World Health Organization. Introduction to adolescence and to adolescent health. In: WHO, eds. WHO Paper. Geneva: WHO - Training Course in Sexual and Reproductive Health Research; 3 September 2012.

2. Registrar General \& Census Commissioner, India, New Delhi, Ministry of Home Affairs, Government of India. The sample registration system of India 2010-11, 2012. Available at: censusindia.gov.in.

3. Ryan RM, Lynch JH. Emotional autonomy versus detachment: revisiting the vicissitudes of adolescence and young adulthood. Child Dev. 1989;60:340-56.

4. Ladd GW, Pettit GS. Parenting and the development of children's peer relationships. In: Bornstein $\mathrm{MH}$, eds. Handbook of Parenting: Practical Issues in Parenting. 2nd ed. Mahwah, NJ, US: Lawrence Erlbaum Associates; 2002: 269-309.

5. Parke RD, Buriel RB. Socialization in the family: ethnic and ecological perspectives. In: Eisenberg N, eds. Handbook of Child Psychology. 5th ed. New York, NY: John Wiley; 1998: 463-552. 
6. Diann M. Ackard, Dianne Neumark-Sztainer, Mary Story, Cheryl Perry. Parent-child connectedness and behavioral and emotional health among adolescents. Am J Prev Med. 2006 Jan;30(1):59-66.

7. Ide K, Parkerson J, Haertel GD, Walberg HJ. Peer group influences on educational outcomes: a quantitative synthesis. J Educ Psychol. 1981;73:47284.

8. Landau A. Peer groups and educational outcomes, 2002. Available at: http://inside.bard.edu/academic/specialproj/darling/b ullying/group2/alison.html. Accessed 24 January 2004.

9. Ryan AM. Peer groups as a context for the socialization of adolescents' motivation, engagement, and achievement in school. Educ Psychol. 2000;35:101-12.

10. Jason Chein, Dustin Albert, Lia O'Brien, Kaitlyn Uckert, Laurence Steinberg. Peers increase adolescent risk taking by enhancing activity in the brain's reward circuitry. Devel Sci. 2011;14(2):1-10.

11. Cleveland MJ, Feinberg ME, Greenberg MT. Protective families in high- and low-risk environments: Implications for adolescent substance use. J Youth Adolesc. 2010;39(2):114-26.

12. Kristjansson AL, Sigfusdottir ID, James JE, Allegrante JP, Helgason AR. Perceived parental reactions and peer respect as predictors of adolescent cigarette smoking and alcohol use. Addict Behav. 2010;35(3):256-9.

13. Hong Y, Li L, Yongyi B, Xunyu X, Shiyue L, Jay E. Family and peer influences on sexual behavior among female college students in Wuhan. Chin Women Health. 2010;50(8):767-82.

14. Amsale C, Yemane B. Peer pressure is the prime driver of risky sexual behaviors among school adolescents in Addis Ababa. Ethiopia World J AIDS. 2012;2:159-64.

15. Prinstein MJ, Dodge KA. Understanding peer influence in children and adolescents. In: Prinstein MJ, Dodge KA, eds. A Book. 5th ed. New York, NY: Guilford; 2008.

DOI: $10.18203 / 2320-1770 . i j r \operatorname{cog} 20150060$

Cite this article as: Khan A, Jain M, Budhwani C. An analytical cross-sectional study of peer pressure on adolescents. Int J Reprod Contracept Obstet Gynecol 2015;4:606-10. 